UDC 504.054

Evelina MICKEVIČIŪTE்*, Agnė ŠLEINIŪTĖ, Inna PITAK, Tamari MUMLADZE, Anastasiia SHOLOKHOVA, Gintaras DENAFAS

Kaunas University of Technology

\title{
MORPHOLOGICAL CONTENT AND RECYCLABILITY OF SEPARATE COLLECTED PACKAGES: A CASE STUDY FOR KAUNAS, LITHUANIA**
}

Packaging materials can arise from a wide range of sources and are commonly used for food, medicine, household appliances, and items to enclose or protect products during distribution, storage, sale, delivery, and use. The choice of material (paper, plastic, glass, wood, metal, multi-layer or other packaging) to be used depends on the type and properties of product, the purpose of packaging, and the price.

The aim of the investigation is to analyse the morphological composition of packaging waste collected separately in Kaunas (Lithuanian) private households and to evaluate its recycling possibilities. The mixture of paper, plastic, and metal packaging waste was analyzed in the winter and spring (one time per month) in the waste management company JSC "Kauno švara".

Keywords: packaging waste, plastics, paper, recycling

DOI: 10.20535/2617-9741.4.2021.248944

*Corresponding author: evelina.mickeviciute@ktu.lt

Received 21 May 2021; Accepted 14 June 2021

Packaging materials can arise from a wide range of sources and are commonly used for food, medicine, household appliances, and items to enclose or protect products during distribution, storage, sale, delivery, and use. The choice of material (paper, plastic, glass, wood, metal, multi-layer or other packaging) to be used depends on the type and properties of product, the purpose of packaging, and the price.

The most common packaging waste is made from paper and cardboard $(40,9 \%)$, in the second place is plastic package waste (19\%), glass packaging waste accounts for $18,7 \%$, woods $-16,1 \%$, metal $-5 \%$ and $0,3 \%$ - other package waste (see Fig. 1) (Eurostat, 2020). However, to sort waste into these fractions is not enough in order to ensure high rate recycling and recover of materials because of different properties of materials.

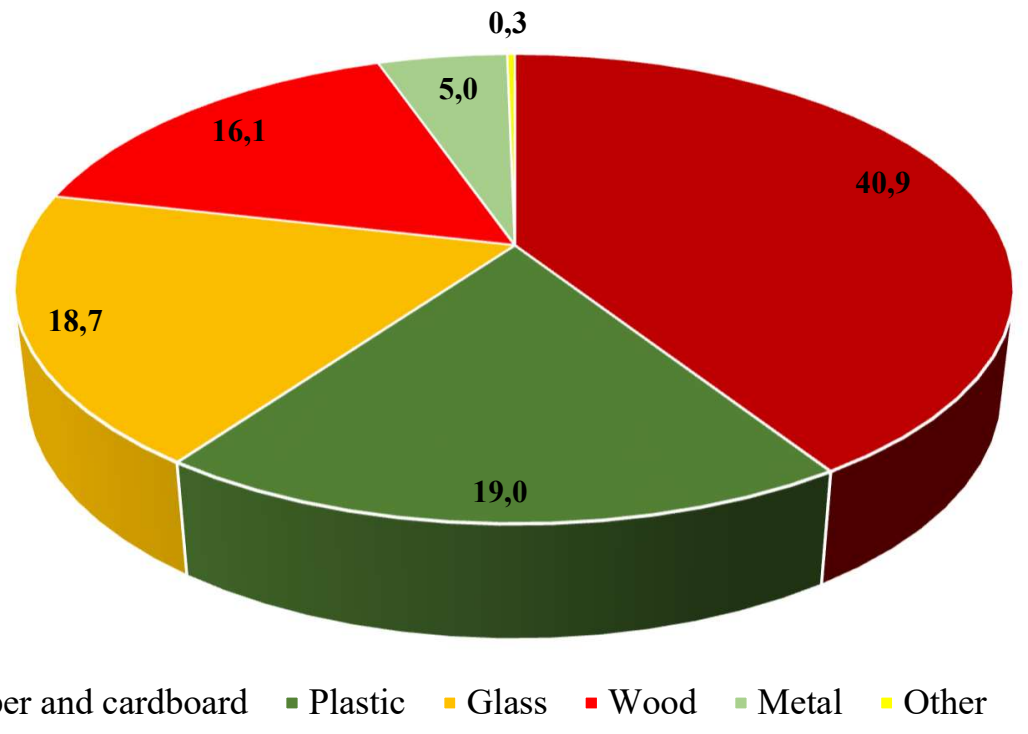

Fig. 1 - Packaging waste generated by packaging material (\%), EU-27, 2018 (Eurostat, 2018)

(C) The Author(s) 2021. Published by Igor Sikorsky Kyiv Polytechnic Institute.This is an Open Access article distributed under the terms of the license CC BY 4.0 (https://creativecommons.org/licenses/by/4.0/), which permits re-use, distribution, and reproduction in any medium, provided the original work is properly cited. 
Plastic is becoming more widely used material in packaging due to its properties such as low density and thermal conductivity, chemical resistance, transparency, lightness, cheap manufacturing process, easy moulding, more simple technological recycling, etc. Most common used polymers for package are thermoplastics, which covers almost $85 \%$ of overall plastic market demand (such as polyethylene terephthalate (PET), high density polyethylene (HDPE), low density polyethylene (LDPE), polyvinyl chloride (PVC), polypropylene (PP), and polystyrene (PS)), while the thermosets account for $15 \%$ overall plastic market (duroplast, polyurethane (PU), polyester resin) (Hestin et al., 2017).

According to the reported data of Eurostat, it is known that the total quantity of generated packaging materials rose by 6,7 million tonnes from 2008 to 2018 (approximately $+9,4 \%$ ). It is estimated that in $2018 \mathrm{EU}$ had $174 \mathrm{~kg}$ of packaging waste per inhabitant (the total volume per inhabitant from 2008 to 2018 increased by $12.4 \mathrm{~kg}$ ). In 2008 2018 the recycling rate of packaging waste increased from $60.4 \%$ to $66.3 \%$ while the recovery (recycling, energy recovery and other forms of recovery) rose from $73.8 \%$ to $80.9 \%$ during this period. All EU countries should achieve the target to recover $60 \%$ material from packaging waste. Although recycling is the main form of recovery in all countries, energy recovery from packaging waste still contributes significantly to the overall recovery rate.

To conserve the planet's resources, it is important to monitor and evaluate packaging waste recycling rates and analyze their potential. To reach the sustainable development goals, EU is committed to recycle $70 \%$ of all packaging waste by 2030, in line with the priorities of the waste hierarchy (European Parliament, 2018). Based on the data of Eurostat (2018), in 2018 Lithuania recycled 60,7 \% package waste and it was in the first place in EU according to the recycling rate of plastic packaging waste, (recycled $69,3 \%$ plastic waste). Although most EU countries have already met some of the EU's packaging recycling targets projected for 2025 or even 2030, they still face with the recycling problems of wooden, aluminium (multilayer) and other plastic packaging waste. To evaluate the possibilities of increase of the package waste recyclability and recovery rates in Lithuania, this study is focused specifically on the analysis of recycling opportunities of the morphological composition of packaging waste collected separately in Kaunas city private households.

The aim of the investigation is to analyse the morphological composition of packaging waste collected separately in Kaunas (Lithuanian) private households and to evaluate its recycling possibilities. The mixture of paper, plastic, and metal packaging waste was analyzed in the winter and spring (one time per month) in the waste management company JSC "Kauno švara".

A group of students manually sorted a randomly picked pile of packaging waste. First, the waste was sorted by different morphological fractions according to the identification marks of international standards on the packaging (1 PET, 5 PP, 6 PS, etc.) (European Parliament and Council Directive 94/62/EC). Further, each fraction was assigned to the groups: currently recyclable, can be recycled outside local businesses, theoretically can be recycled, recycling options are being investigated and not recyclable (Šleiniūtè et al, 2021).

In a morphological study carried out in the sample of 21 st of January 2021, the largest amount of sorted mixed packaging waste was made up of plastic and composites $-53,5 \%$, mix small fraction $-13.8 \%$, paper and cardboard $-13 \%$, metal $-9,5 \%$ and textile $-6,3 \%$ and glass $-3,9 \%$ (see Figure 2 ).

In the sample of the 15th of March 2021, the same trend remained, only the percentage distribution of waste in fractions has changed, plastics decreased (44\%), increased the amount of paper and cardboard $(25,8 \%)$ and mix small fraction $(18,5 \%)$, while metal and textile fractions percentage composition slightly decreased. In the sample of the 15th of April 2021, the largest fraction of packaging waste was still plastics - 34\%, a significant increase was observed in small unsortable fraction $-30,7 \%$, the composition of paper remained as in March $-25,4 \%$, a slight decrease in metal $-7,4$ and textiles amounted to $1 \%$. Were also detected wood $0,5 \%$ and electrical and electronic equipment $-0,5 \%$.

A similar but slightly better situation was observed in the March and April samples (see Figure 3). 59,1\% of all package waste in sample of March are recyclable, they can actually be recycled 4,3\%, possible to recycle $10 \%$, investigated for recycling $1,5 \%$ and $25,1 \%$ not recyclable. $49,5 \%$ of all package waste in sample of April are recyclable, can be recycled 9,2 \%, possible to recycle 4,9\%, investigated for recycling 0,8\% and 35,6\% not recyclable. 


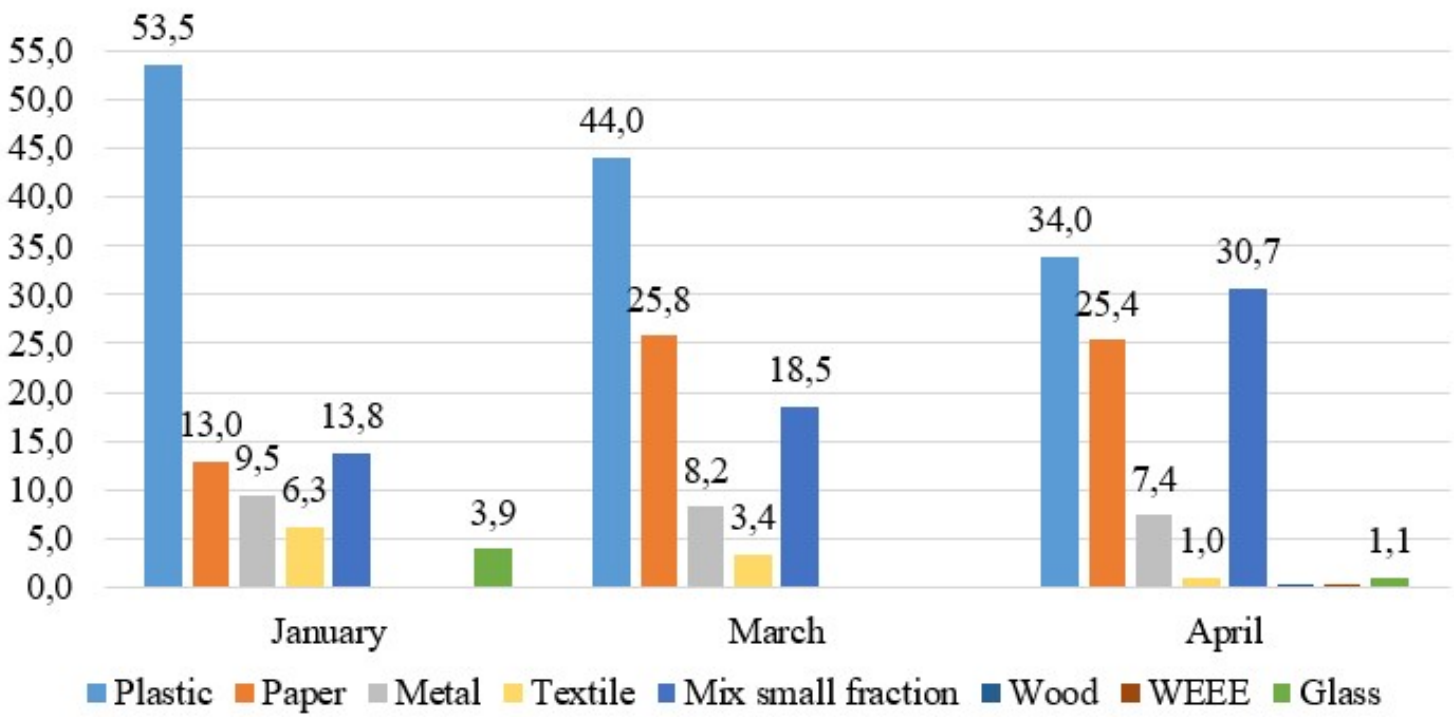

Fig. 2 - Distribution of packaging waste mixture in January, March, and April in Kaunas city private households, \%

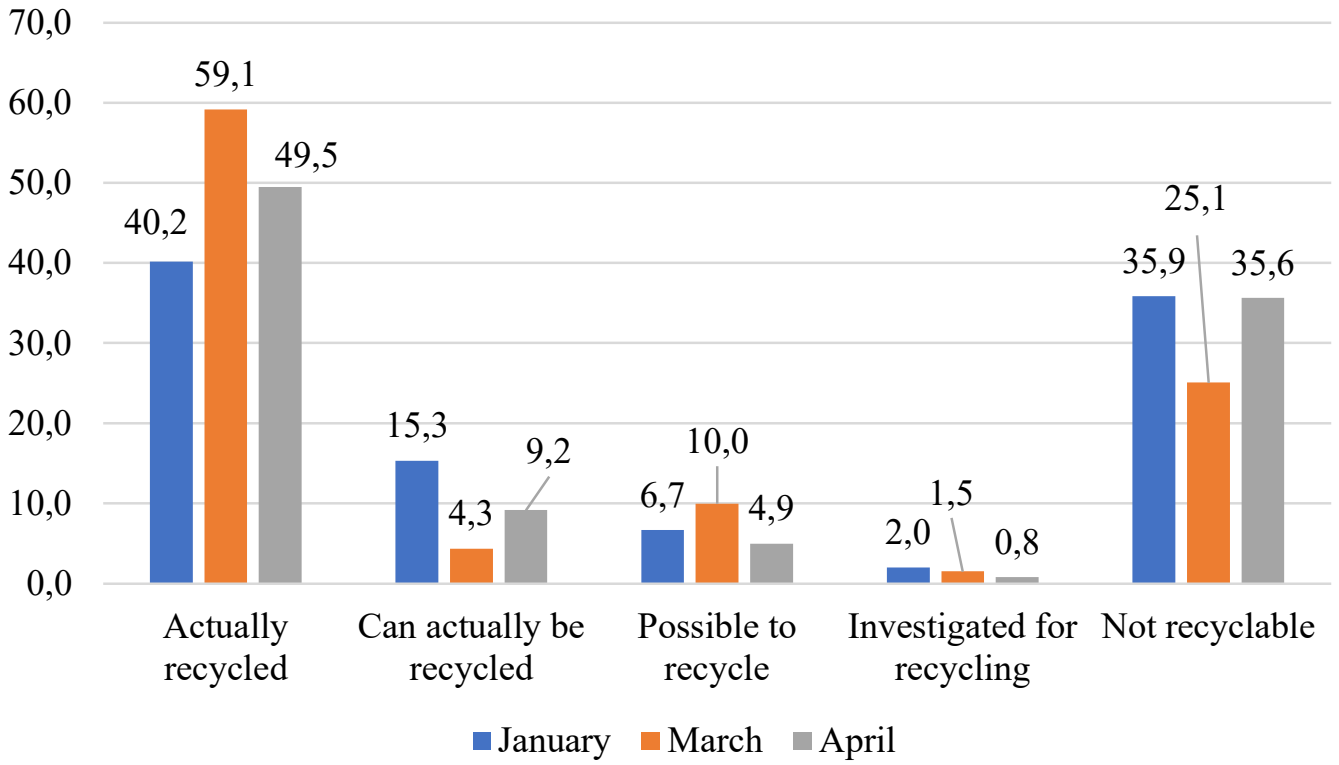

Fig. 3 - Recyclability possibilities of package mixture waste composition in Kaunas city private households in January, March, and April, \%

Packaging waste contains various types of materials. The distribution of percentage composition in the studied samples is shown in the picture below (see Figure 4).

The composition of sorted plastic in the packaging waste mixture in private households in Kaunas city is shown in a picture below (see Figure 5). Based on the different recycling options for the same code plastic waste and the quantities, morphological fractions of plastic according to the identification marks are separated to subs fraction based on the physical properties (soft, rigid, foam). 


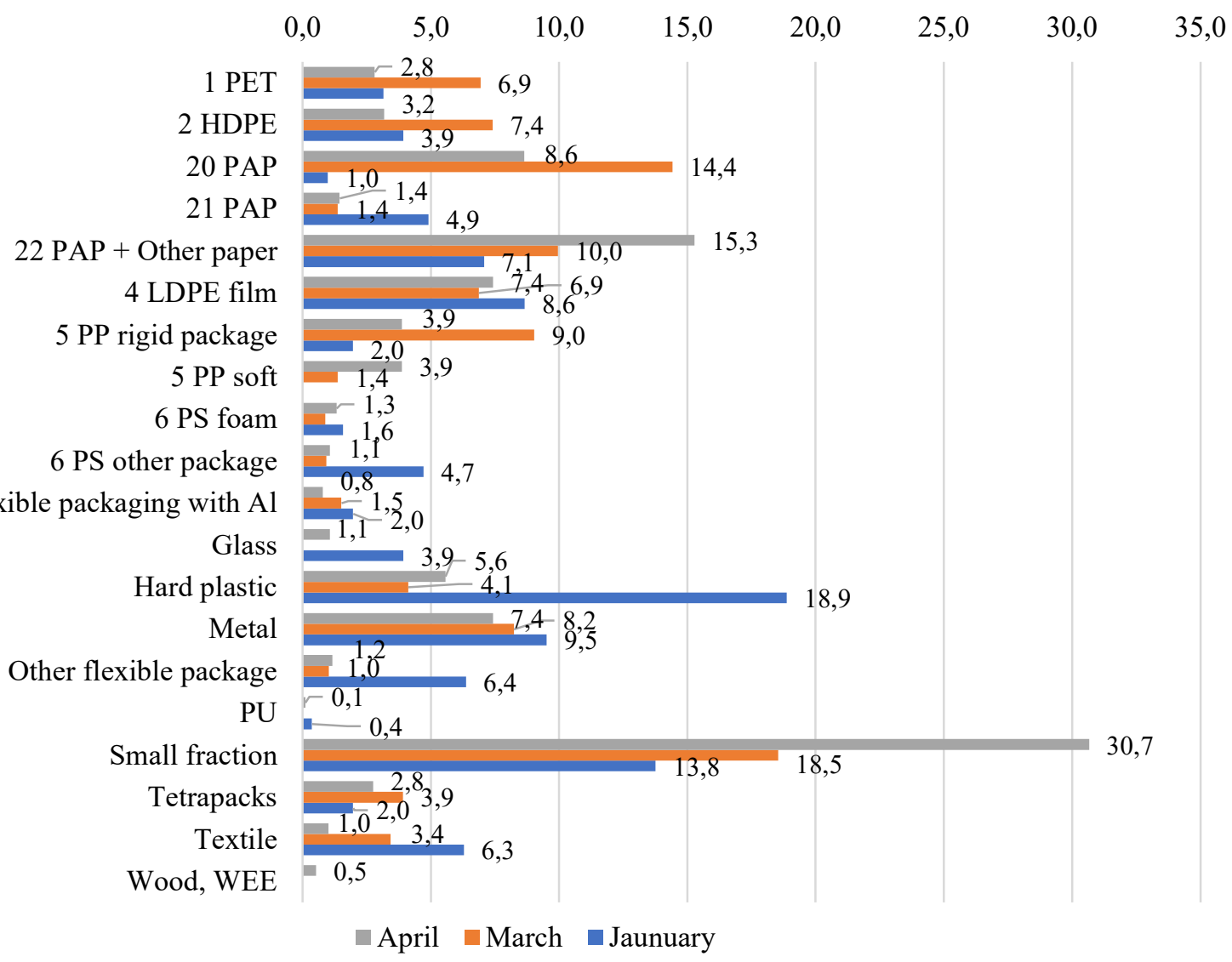

Fig. 4 - Distribution of packaging waste mixture in Kaunas city private households in January, March, and April, \%

Assessing the plastic part in January, March and April waste samples separately, it was observed that in all samples the largest amount was of plastics that are actually recycled: $33,1 \%$ of plastics in January (including 5,9 \% PET, 16,2 \% LDPE, 7,3 \% HDPE, 3,7 \% tetrapacks), 57,1 \% in March (including 15,8 \% PET, 15,6 \% LDPE, 16,8 $\%$ HDPE, 8,9 \% tetrapacks), 47,7 \% April (including 8,3\% PET, 21,9\% LDPE, 9,4 \% HDPE, 8, $1 \%$ tetrapacks) (see Figure 6).

The share of plastics that could be recycled in other companies was 21,2 \% in January, 6,7 \% in March, and 12,4 $\%$ in April (polystyrene foam can be recycled by JSC "R\&R Ideas", polyurethane can be recycled by JSC "AVAGO", Vilnius).

The share of plastics, which could theoretically be recycled and is made up of other rigid packaging, was $12,5 \%$ in January (PP - 3,7 \%; PS - 8,8 \%), in March - 25,7 \% (PP - 23,6\%; PS - 2,1 \%), and in April - 25,9 \% (PP - 22,8 $\%$; PS $-3,1 \%$ ). Unfortunately, there are no companies processing them in Lithuania yet, but JSC "Retroplast" is a company in Vilnius district that buys these plastics suitable for recycling.

Flexible packaging containing aluminium accounted for 3,7 \% of the total plastic waste stream in January, 3,4 \% in March, and 2,3\% in April. The possibilities of their recycling are currently being investigated by the Department of Environmental Technology of KTU (Rimšaitè et al, 2019).

Not recyclable fraction of plastics consists other plastic marked number 7 and partially of hard plastics, respectively, the share of non-recyclable plastic waste stream suitable only for incineration was $29,5 \%$ in January, 7 $\%$ in March, and 11,6\% in April. 


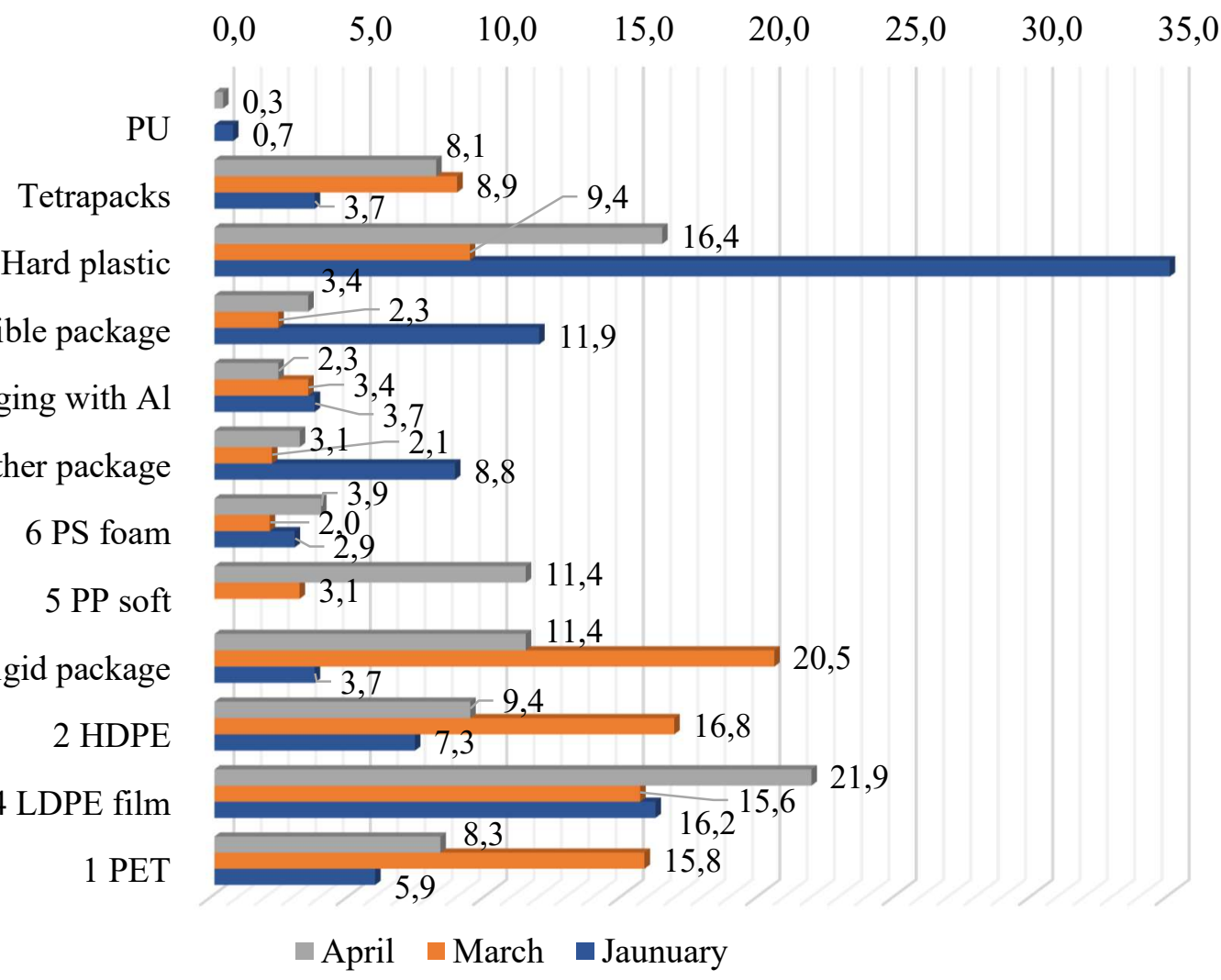

Fig. 5 - Plastic composition in package waste mixture in Kaunas city private households in January, March, and April, \%

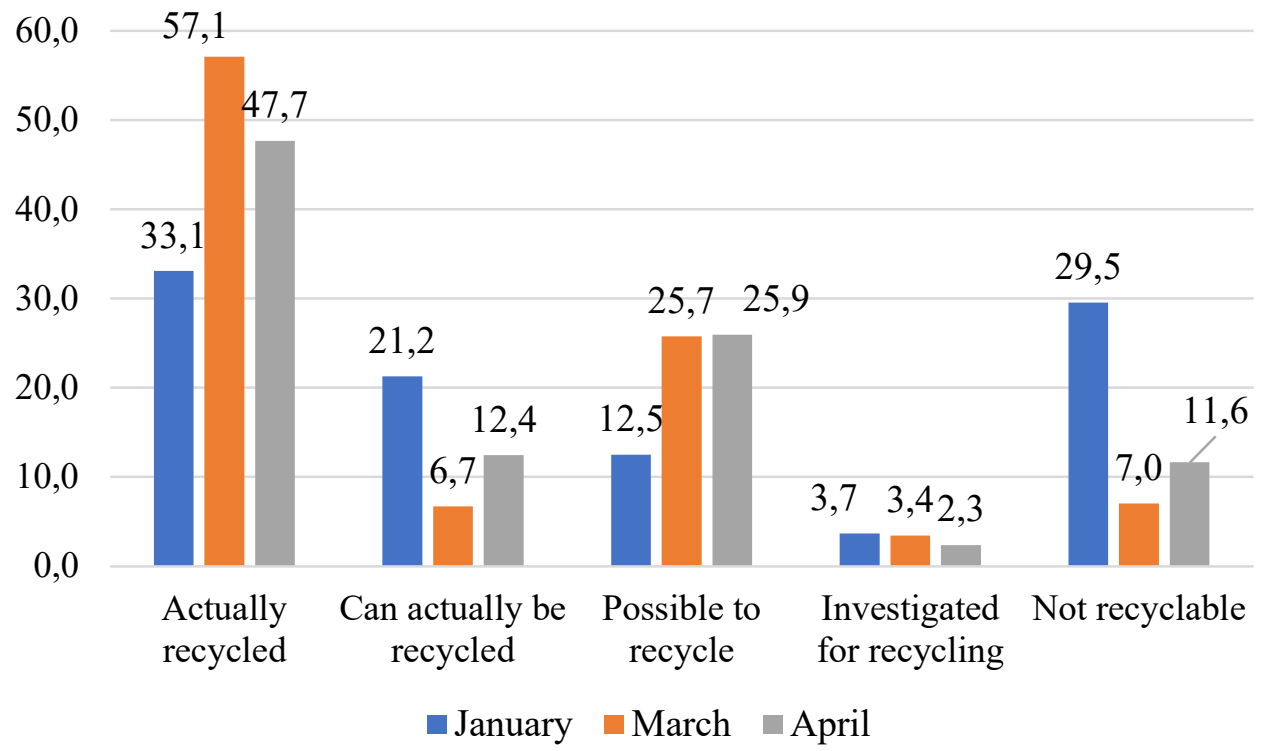

Fig. 6 - Recyclability possibilities of plastics waste composition by month in Kaunas city private households in January, March, and April, \% 
To achieve the goals of the circular economy, the development of an efficient method of recycling waste is a favorable way to save natural resources, as the materials extracted from waste can be used as a raw material in the same or another production. The study has shown that according to the obtained result studied from Kaunas private households packaging waste, it is possible to recycle about $62-73 \%$ of collected package waste stream depending on the morphological composition. Other non-recyclable wastes are incinerated. About $2 \%$ of waste, which recycling possibilities are under the investigation on the extraction of raw materials, are currently incinerated. It is possible to recycle 66-90\% of plastic waste stream from package waste collected by JSC "Kaunas švara" depending on the morphological composition, about $3 \%$ of multilayer package with aluminium are investigated for recycle possibilities.

\section{Acknowledment JSC "Kauno švara".}

\section{References:}

1. European Environment Agency, (2019). Packaging waste recycling rates in Europe by country. Prestudy report [viewed on 27.04.21]. Access via the Internet: https://www.eea.europa.eu/data-and-maps/daviz/packagingwaste-recycling-2\#tab-chart_1

2. Eurostat, (2020). Packaging waste statistics. Prestudy report [viewed on 27.04.21]. Access via the Internet: https://ec.europa.eu/eurostat/statisticsexplained/index.php?title=Packaging_waste_statistics\#Waste_generation_ by_packaging_material

3. European Parliament, (2018). The circular economy package: new EU targets for recycling. Prestudy report [viewed on 27.04.21]. Access via the Internet: https://www.europarl.europa.eu/news/en/headlines/society/20170120STO59356/the-circular-economypackage-new-eu-targets-for-recycling

4. Hestin, M., Mitsios, A., Said, S. A., Fouret, F., Berwald, A. \& Senlis, V., (2017). Deloitte Sustainability Blueprint for plastics packaging waste: Quality sorting \& recycling. Final report. Access via the Internet: https://www2.deloitte.com/content/dam/Deloitte/my/Documents/risk/my-risk-blueprint-plastics-packagingwaste-2017.pdf

5. European Parliament and Council Directive 94/62/EC on packaging and packaging waste. Official Journal of the European Communities. Access via the Internet: https://eur-lex.europa.eu/legalcontent/EN/TXT/PDF/?uri=CELEX:31997D0129\&from=CS

6. Rimšaite, A., Mumladze, T., \& Denafas,G. (2019). Feasibilities of Aluminium Recovery from Combined Packaging Waste. International Journal of Agriculture \& Environmental Science, 6(6), $103-111$. https://doi.org/10.14445/23942568/IJAES-V6I6P114

7. Šleiniūtè, A., Mumladze, T., Pitak, I. \& Denafas, G. (2021). Recyclability of separate collected municipal solid waste fractions: a case study for Kaunas, Lithuania. 